\title{
Quality of Life and HIV Adherence Self-efficacy of Adolescents and Young Adults Living With Perinatal HIV in Chiang Mai, Thailand: A Cross-sectional Study
}

Linda Aurpibul ( $\square$ lindaa@rihes.org)

Chiang Mai University https://orcid.org/0000-0003-0246-8187

Chanidapa Pradsarakee

Chiang Mai University

Kamolrawee Sintupat

Chiang Mai University

Nongyow Wongnum

Chiang Mai University Faculty of Medicine

Tawalchaya Chotecharoentanan

Chiang Mai University

Tavitiya Sudjaritruk

Chiang Mai University Faculty of Medicine

\section{Research}

Keywords: perinatal HIV infection, adherence, psychological health

Posted Date: July 9th, 2020

DOI: https://doi.org/10.21203/rs.3.rs-40624/v1

License: (a) (i) This work is licensed under a Creative Commons Attribution 4.0 International License. Read Full License 


\section{Abstract}

Background:Currently there are many children with perinatal HIV infection (PHIV) in Thailand who have survived on effective treatment, and grown up into adolescents and young adults (AYA). We determined their quality of life and HIV adherence self-efficacy.

Methods: This cross-sectional study was conducted at Research Institute for Health Sciences, Chiang Mai University, Thailand in 2018. Inclusion criteria were: 1) aged between 15-25 years, 2) living with perinatal HIV infection, and 3 ) receiving ART. Those with mental, physical, or communication problems and could not provide responses independently were excluded. The WHO-quality of life-BREF questionnaire and the HIV Treatment Adherence Self-Efficacy Scale (HIV-ASES) were usedin collecting data by self-administered questionnaires on mobile device.

Results: A hundred and eleven AYA-PHIV were included; 52 (47\%) were female. Their median age, and duration on ART were 20.2 (IQR 18.2-22.6), and 14.1 (IQR 10.4-14.8) years, respectively. Approximately half (59.4\%) of AYAPHIV rated their overall QOL as favorable (41.4\% good,and $18.0 \%$ very good), whereas $35.1 \%$ rated as neither poor nor good. The mean \pm SD domain-wise scores were $54.71 \pm 10.80,59.79 \pm 13.17,63.19 \pm 20.56$, and $65.32 \pm$ 16.74inthe physical health, psychological health,social relationship, and environmental health, respectively. The overall mean HIV-ASES score was $7.79 \pm 1.95$, with a trend towards higher scores in female than male AYA-PHIV. A positive correlation between HIV-ASES and QOL was observed $(r=0.268, p=0.005)$.

Conclusion: Most of AYA-PHIVin Thailand had a favorable QOL and optimal HIV-adherence self-efficacy.Attention should be paid on strengthen their physical and psychological health, with continuous social support. Intervention to boost their HIV-adherence self-efficacy when entering adult life is warranted.

\section{Background}

HIV has been a significant worldwide health challenge for a few decades. Globally in 2018, estimated 37.9 million people living with HIV; 5.9 million were in Asia and the Pacific (1). More than half of them had access to the effective antiretroviral treatment (ART), including many children with perinatal HIV infection (PHIV). Changing from a deadly disease to a chronic manageable illness, children with PHIV have survived and grown up into adolescents and young adults (AYA). Meanwhile, focusing of treatment has shifted from fighting virus to ensuring well-being for individual living with HIV.

Thailand was among the first Asian countries where children with PHIV had access to ART through the national AIDS program since 2000. Living with HIV infection since childhood might affect AYA as they had to cope with HIV-related symptoms, the need to take medication daily for extended period, the need to keep secret, family crisis i.e. loss of beloved parents/ caregivers, and other co-morbidities either from HIV infection itself or the treatment. Those factors could affect their physical, mental, as well as social well-being $(2,3)$.

Quality of life (QOL) is generally defined as an individual's satisfaction and subjective well-being with life. It is a multidimensional construct combining subjective evaluation of both positive and negative aspects of life (4). QOL is considered an important outcome measure in studies of HIV/AIDS treatment. One UNAIDS survey reflected a social trend of noting mental health when considering public health interventions to prevent and control HIV/AIDS. It supported including QOL as a 'fourth 90' for HIV/AIDS where $90 \%$ of people with virologic 
suppression have good health-related QOL (5). Psychosocial impacts of HIV have been documented in many studies among perinatally HIV-infected population $(2,6)$. The findings from previous pediatric QOL studies were inconsistent. The study in Thai and Cambodian children (mean age 6.3 years) reported lower QOL scores in children with HIV infection than healthy controls (7). In contrary, another Thai study found no difference in healthrelated QOL between adolescents with PHIV (mean age 14.6 years) and healthy control, by self-report; whereas, parent-proxy report revealed even higher health-related QOL among PHIV than in control group (8). The QOL assessment by parent proxy and self-report among school-age children and adolescent from 6-18 years in Uganda documented sustained deficits in multiple QOL domains when compared with healthy uninfected and HIV-exposed uninfected groups (9). The Dutch study reported no differences in the mean health-related QOL subscales between children living with HIV, and either healthy control groups or country norm, but higher proportion of children in the HIV group had impaired health-related QOL (10). In the Spanish study among youth living with PHIV (mean age 23.36 years) revealed lower scores in physical and mental health than HIV negative youth (11). Learning more about QOL in AYA may help to understand how they perceived and provide us an opportunity to intervene as needed.

As known that adherence to ART is critical in controlling HIV replication (12). Treatment compliance has always been a problem in adolescents during their transitional period of life. The meta-analysis demonstrated that the overall rate of adherence in adolescents and young adults globally was only $62 \%(13)$. Meanwhile, young population with PHIV in Africa and Asia had higher rate of adherence $(>70 \%)$ when compared to adolescents in Europe and North America (50-60\%). The difference was explained by multiple factors including difference in health care systems, communities affected by HIV, medication related issues, and effects of being enrolled into clinical trials. At individual level, knowledge alone might not lead to favorable behaviors (14). Adherence selfefficacy, defined as confidence in one's ability to carry out certain treatment plans i.e. taking medication on time regularly is an important determinant of ART adherence (15). Moreover, there were studies demonstrated that selfefficacy is an important predictor of QOL among patients with chronic diseases (16). The Chinese study showed that self-efficacy, as well as medication adherence were significant predictors of QOL in adults living with HIV (17).

We hypothesized that with treatment accessibility and variety of support provided to individuals living with HIV in Thailand, the QOL of growing-up AYA-PHIV would be good. The aim of this study is to assess the overall quality of life of Thai AYA-PHIV, to determine their responses in each domain, and rate their HIV-adherence self-efficacy. We also delineate factors associate with QOL in this population.

\section{Methods}

\section{Study design and population}

The cross-sectional study was conducted at the Research Institute for Health Sciences, Chiang Mai University, Chiang Mai, Thailand in December 2018- April 2019. Inclusion criteria were: 1) age between 15-25 years, 2) having perinatal HIV infection, and 3) receiving ART. Those with profound mental, physical, or communication problems which prohibited them from providing their response independently were excluded. Study participants were recruited from the pediatric HIV clinic in the Chiang Mai University Hospital, and from HIV clinics in other neighboring hospitals via community networks. Participants were approached during their routine visit for HIV treatment. 


\section{Data collection and tools}

Data was collected by self-administered questionnaires on mobile device using REDCap Software - Version 6.2.0 (C) 2020 Vanderbilt University. Quality of life (QOL) was assessed by WHOQOL-BREF. It produced a profile with four domain scores (physical health, psychological health, social relationship, and environmental health), and two individually scored items (18). AYA were asked to rate their QOL in the past two weeks on a five-point Likert scale. Scores were scaled in a positive direction with higher scores indicating better QOL. Some items required to be reversed before scoring; raw scores for each domain was calculated by adding values of single items and transformed to a score ranging from 0-100. A score is considered as good if it is $>50 \%$ of the maximum attainable score, both domain-wise and overall. Higher scores indicated a better QOL. The tool was previously assessed for reliability and validity in Thai patients with HIV/AIDS; the Cronbach's alpha ranged from 0.61 to 0.81 across domains (19). The self-efficacy for treatment adherence was assessed with the HIV Adherence SelfEfficacy Scale (HIV-ASES) with a 12-item scale of patient confidence to carry out important treatment-related behaviors related to adhering to treatment plans in the face of barriers; the response ranges from 1 (cannot do it at all) to 10 (certain can do it). Item scores were averaged for each participant with higher scores indicating higher adherence self-efficacy. It has been validated and demonstrated robust internal consistency with test-retest reliability (20).

\section{Statistical analysis}

Statistical analysis was performed using SPSS Statistics for Windows, Version 17.0. Chicago: SPSS Inc; 2008. Descriptive analysis was used to present socio-economic and demographic characteristics of study participants, as well as the domain-wise raw and transformed scores of WHO QOL-BREF. Continuous variables were presented as mean (standard deviation, SD) or median (interquartile range, IQR), as appropriate. Categorical variables were presented in number (percentage).

Bivariate and multivariate logistic regression models were generated by making QOL as a dichotomous categorical dependent variable (Good or very good: favorable QOL, and neither good nor bad, bad, very bad: unfavorable QOL). All independent variables were included in multivariate, irrespective of significant level in bivariate analysis. Adjusted odds ratio and 95\% confident interval was computed. A p-value of $<0.05$ for twosided tests was considered to be statistically significant. Correlation between HIV adherence self-efficacy and overall QOL was determined by linear regression.

\section{Results}

\section{Characteristics of study participants}

A hundred and eleven AYA-PHIV were included; 52 (47\%) were female. Their median age, and duration on ART were 20.2 (interquartile range, IQR 18.2-22.6), and 14.1 (IQR 10.4-14.8) years, respectively. The ART regimens used were nevirapine-, efavirenz-, and protease inhibitor-based in 20 (18\%), 51(46\%), and 35 (32\%), respectively. Forty-four (40\%) have quited school at any levels and worked full time, while $25 \%$ were in primary/secondary school, $22 \%$ in vocational school, and $14 \%$ in college/university or higher degree. Majority of them (65\%) resided outside the city within Chiang Mai province (Table 1). 
Table 1

Socio-demographic characteristics of adolescents and young adults living with perinatal HIV $(n=111)$

\begin{tabular}{|c|c|}
\hline Characteristics & Total \\
\hline Number of participants & 111 \\
\hline Female sex & $52(47 \%)$ \\
\hline Age (years), mean \pm SD & $20.2(2.6)$ \\
\hline Age (years), median (IQR) & $20.2(18.2-22.6)$ \\
\hline Duration on ART (years), mean \pm SD & $12.7(3.1)$ \\
\hline Duration on ART (years), median (IQR) & $14.1(10.4-14.8)$ \\
\hline \multicolumn{2}{|l|}{ Current ART regimen } \\
\hline Nevirapine-based & $20(18 \%)$ \\
\hline Efavirenz-based & $51(46 \%)$ \\
\hline Protease inhibitor-based & $35(32 \%)$ \\
\hline Other regimens & $5(5 \%)$ \\
\hline \multicolumn{2}{|l|}{ Current educational status } \\
\hline Primary/secondary school & $28(25 \%)$ \\
\hline Vocational school & $24(22 \%)$ \\
\hline Bachelor's degree or higher & $15(14 \%)$ \\
\hline Finished schooling at any level & $44(40 \%)$ \\
\hline \multicolumn{2}{|l|}{ Working status } \\
\hline Full time job & $44(40 \%)$ \\
\hline Part time job & $10(9 \%)$ \\
\hline Do not work & $57(51 \%)$ \\
\hline \multicolumn{2}{|l|}{ Primary caregiver during childhood } \\
\hline Biological parents & $42(38 \%)$ \\
\hline Other relatives & $45(41 \%)$ \\
\hline Other non-relatives & $24(22 \%)$ \\
\hline \multicolumn{2}{|l|}{ Residential area } \\
\hline Within Chiang Mai city & $21(19 \%)$ \\
\hline Other districts in Chiang Mai Province & $72(65 \%)$ \\
\hline Other provinces & $18(16 \%)$ \\
\hline
\end{tabular}




\begin{tabular}{|l|}
\hline Characteristics \\
Data in number (\%), mean (standard deviation, SD), or median (interquartile range, IQR) \\
as appropriate \\
ART antiretroviral treatment
\end{tabular}

\section{Overall quality of life and general health (Table 2)}

Table 2

Frequency distribution of selected items of WHO- quality of life-BREF in adolescents and young adults living with perinatal HIV

\begin{tabular}{|c|c|c|c|c|c|}
\hline Questions & & & & & \\
\hline $\begin{array}{l}\text { How would you rate your quality of } \\
\text { life? }\end{array}$ & Very poor & Poor & $\begin{array}{l}\text { Neither poor } \\
\text { nor good }\end{array}$ & Good & $\begin{array}{l}\text { Very } \\
\text { good }\end{array}$ \\
\hline Number of responses (\%) & $4(3.6)$ & $2(1.8)$ & $39(35.1)$ & $\begin{array}{l}46 \\
(41.4)\end{array}$ & $\begin{array}{l}20 \\
(18.0)\end{array}$ \\
\hline $\begin{array}{l}\text { How satisfied are you with your } \\
\text { health? }\end{array}$ & $\begin{array}{l}\text { Very } \\
\text { dissatisfied }\end{array}$ & Dissatisfied & $\begin{array}{l}\text { Neither } \\
\text { satisfied nor } \\
\text { dissatisfied }\end{array}$ & Satisfied & $\begin{array}{l}\text { Very } \\
\text { satisfied }\end{array}$ \\
\hline Number of responses (\%) & $27(24.3)$ & $32(28.8)$ & $37(33.3)$ & $11(9.9)$ & $4(3.6)$ \\
\hline $\begin{array}{l}\text { How much do you need any medical } \\
\text { treatment to function in your daily } \\
\text { life? }\end{array}$ & Not at all & A little & $\begin{array}{l}\text { A moderate } \\
\text { amount }\end{array}$ & $\begin{array}{l}\text { Very } \\
\text { much }\end{array}$ & $\begin{array}{l}\text { An } \\
\text { extreme } \\
\text { amount }\end{array}$ \\
\hline Number of responses (\%) & $2(1.8)$ & $6(5.4)$ & $41(36.9)$ & $\begin{array}{l}38 \\
(34.2)\end{array}$ & $\begin{array}{l}24 \\
(21.6)\end{array}$ \\
\hline
\end{tabular}

Thirty-nine (35.1\%) AYA-PHIV in this study rated their QOL as neither poor nor good; 46 (41.4\%) rated good, and 20 (18.0\%) rated very good. When considered the satisfaction in their own health, 37 (33.3\%) replied as neither satisfied nor dissatisfied while 32 (28.8\%) dissatisfied, and 27 (24.3\%) very dissatisfied. Forty-one (36.9\%), 38 (34.2\%), and 24 (21.6\%) perceived their need for medical treatment to function in their daily life in a moderated amount, very much, and an extremely amount, respectively.

Domain wise scores (Table 3) 
Table 3

Descriptive statistics of domain wise raw (4-20) and transformed score (0-100) of WHO quality of life-BREF in adolescents and young adults living with perinatal HIV

\begin{tabular}{|c|c|c|c|c|c|c|c|c|}
\hline \multirow[t]{2}{*}{ Domains } & \multicolumn{4}{|c|}{ Attained raw score } & \multicolumn{4}{|c|}{ Attained transformed score } \\
\hline & minimum & maximum & $\begin{array}{l}\text { mean } \\
(\mathrm{SD})\end{array}$ & $\begin{array}{l}\text { Median } \\
\text { (IQR) }\end{array}$ & minimum & maximum & $\begin{array}{l}\text { mean } \\
(S D)\end{array}$ & $\begin{array}{l}\text { Median } \\
\text { (IQR) }\end{array}$ \\
\hline $\begin{array}{l}\text { Physical } \\
\text { health }\end{array}$ & 8 & 17 & $\begin{array}{l}12.73 \\
(1.73)\end{array}$ & $\begin{array}{l}13 \\
(11- \\
14)\end{array}$ & 25 & 81 & $\begin{array}{l}54.71 \\
(10.80)\end{array}$ & $\begin{array}{l}56 \\
(44- \\
63)\end{array}$ \\
\hline $\begin{array}{l}\text { Psychological } \\
\text { health }\end{array}$ & 7 & 17 & $\begin{array}{l}13.56 \\
(2.11)\end{array}$ & $\begin{array}{l}13 \\
(12- \\
15)\end{array}$ & 19 & 81 & $\begin{array}{l}59.79 \\
(13.17)\end{array}$ & $\begin{array}{l}56 \\
(50- \\
69)\end{array}$ \\
\hline $\begin{array}{l}\text { Social } \\
\text { relationship }\end{array}$ & 4 & 20 & $\begin{array}{l}14.11 \\
(3.29)\end{array}$ & $\begin{array}{l}15 \\
(12- \\
16)\end{array}$ & 0 & 100 & $\begin{array}{l}63.19 \\
(20.56)\end{array}$ & $\begin{array}{l}69 \\
(50- \\
75)\end{array}$ \\
\hline $\begin{array}{l}\text { Environmental } \\
\text { health }\end{array}$ & 4 & 20 & $\begin{array}{l}14.43 \\
(2.67)\end{array}$ & $\begin{array}{l}14 \\
(13- \\
16)\end{array}$ & 0 & 100 & $\begin{array}{l}65.32 \\
(16.74)\end{array}$ & $\begin{array}{l}63 \\
(56- \\
75)\end{array}$ \\
\hline
\end{tabular}

\section{- Physical health domain}

The mean (SD) transformed scores in the physical health domain was $54.71 \pm 10.80$. Many AYA-PHIV felt that physical pain and discomfort prevented (43.2\% and $26.1 \%$ very much and an extremely amount, respectively) them from doing what they need to do. Almost all perceived their dependence on medical treatment to function in their daily life (36.9\%, 34.2\% and $21.6 \%$ moderately amount, very much, and extremely amount, respectively). However, majority of them enjoyed life $(31.5 \%, 36.9 \%$, and $26.1 \%$ moderately amount, very much, and extremely amount, respectively), and had enough energy for everyday life (27.9\%, 38.7\%, and $25.2 \%$ moderately, mostly, and completely, respectively). Regarding working capacity, 9\% felt dissatisfied, while many (44.1\%) felt neither satisfied nor dissatisfied; $32.4 \%$ and $10.8 \%$ of AYA-PHIV were satisfied and very satisfied with their working capacity, respectively.

\section{- Psychosocial health domain}

The mean (SD) transformed scores in the psychosocial health domain was $59.79 \pm 13.17$. Most of AYA-PHIV were able to $(27.0 \%$ moderately, $24.3 \%$, mostly, and $26.1 \%$ completely) accept their bodily appearance. Low self-esteem was rated by $17.1 \%$ of AYA-PHIV in this study, whereas $46.8 \%$ were neither satisfied nor unsatisfied, and $22.5 \%$ were satisfied with their ability to perform own daily activities. Approximately one-third (35.1\%) were satisfied with themselves; $36.0 \%$ were neither satisfied nor unsatisfied. Having negative feelings (blue mood, despair, anxiety, depression) were experienced quite often, very often, and always in $32.4 \%, 46.8 \%$, and $17.1 \%$ of AYA-PHIV, respectively.

\section{- Social relationship domain}

The mean (SD) transformed scores in the social relationship domain was $63.19 \pm 20.56$. Fourteen out of 111 AYAPHIV (12.6\%) were dissatisfied, whereas 30.6\%, 39.6\%, and 13.5\% were neither satisfied nor dissatisfied, satisfied, and very satisfied, respectively, with their personal relationship. Half of them were satisfied with social support 
(35.1\% satisfied, and $14.4 \%$ very satisfied). Majority of AYA-PHIV were satisfied (41.4\%) with their sexual life, and $16.2 \%$ were very satisfied; whereas $36.0 \%$ were neither satisfied nor dissatisfied.

\section{- Environmental health domain}

The mean (SD) transformed scores in the environmental health domain was $65.32 \pm 16.74$. Nearly a third (30.6\%) of study participants thought that their physical environment was not healthy at all. Meanwhile, $31.5 \%$ said a little, and $27.9 \%$ rated moderate amount. However, their living places were considered as neither satisfied nor dissatisfied, satisfied, and very satisfied by $27.0 \%, 33.3 \%$, and $30.6 \%$, respectively. Most felt that their daily life was safe (27.9\% a moderate amount, $37.8 \%$ very much, and $24.3 \%$ extremely). Most AYA-PHIV perceived that information they need in their daily life was available (32.4\% moderately, 29.7 mostly, and $32.4 \%$ completely). A large number of AYA-PHIV (36.0\%) were very satisfied, and $36.9 \%$ were satisfied with their access to and quality of health and social care.

\section{Factors associated with QOL (Table 4)}

Table 4

Bivariate and multivariate regression model explaining overall quality of life in adolescents and young adults living with perinatal HIV

\begin{tabular}{|llll|}
\hline Variables & Coding & OR (95\% Cl) & aOR (95\% Cl) \\
\hline Sex & Female & $0.988(0.462-2.111)$ & $0.983(0.433-2.231)$ \\
\hline Age (years) & Male & 1 & 1 \\
\hline & $\geq 20$ & $0.777(0.522-2.390)$ & $1.226(0.534-2.814)$ \\
\hline Educational status & $<20$ & 1 & 1 \\
\hline & Studying & $0.374(0.162-0.866)$ & $0.391(0.166-0.923)$ \\
\hline Primary caregiver during childhood & Biological parents & $0.792(0.351-1.785)$ & $0.904(0.388-2.107)$ \\
\hline & Others & 1 & 1 \\
\hline ART regimens & Efavirenz-based & $1.247(0.564-2.758)$ & $1.220(0.528-2.818)$ \\
\hline & Other regimens & 1 & 1 \\
\hline Cl confident interval; ART antiretroviral treatment & & \\
\hline
\end{tabular}

Factors potentially associated with QOL in AYA-PHIV was included in the bivariate logistic regression model. It revealed that with an increase in age ( $\geq 20$ years) of AYA-PHIV (OR $0.777(0.522-2.390)$ ), studying (OR 0.374 (0.162-0.866)), and living with biological parents during childhood (OR $0.792(0.351-1.785)$ ) were associated with unfavorable QOL (score < 50). Meanwhile, receiving EFV-based ART regimens (OR $1.247(0.564-2.758)$ ) was associated with favorable QOL (score $\geq 50$ ). However, no statistical significant was evidenced for any association.

Multivariate logistic regression after adjustment revealed favorable QOL among those with older age ( $\geq 20$ years) (OR 1.226 (0.534-2.814)), and using EFV-based ART regimens (OR 1.220 (0.528-2.818)), whereas studying (OR 
0.391 (0.166-0.923)) and living with biological parents during childhood (OR $0.904(0.388-2.107))$ found to associate with unfavorable QOL. No significant association could be established with these variables.

HIV adherence self-efficacy (Table 5)

Table 5

Descriptive statistics of HIV Treatment Adherence Self-Efficacy Scale of adolescents and young adults living with perinatal HIV infection

\begin{tabular}{|c|c|c|c|c|}
\hline Questions & Total & Female & Male & $\begin{array}{l}\text { p- } \\
\text { value }\end{array}$ \\
\hline $\begin{array}{l}\text { 1. Stick to your treatment plan even when side effects begin to interfere } \\
\text { with daily activities. }\end{array}$ & $\begin{array}{l}7.65 \\
(2.50)\end{array}$ & $\begin{array}{l}7.73 \\
(2.35)\end{array}$ & $\begin{array}{l}7.59 \\
(2.48)\end{array}$ & 0.755 \\
\hline 2. Integrate your treatment into your daily routine. & $\begin{array}{l}8.08 \\
(2.19)\end{array}$ & $\begin{array}{l}8.25 \\
(2.27)\end{array}$ & $\begin{array}{l}7.90 \\
(2.12)\end{array}$ & 0.400 \\
\hline $\begin{array}{l}\text { 3. Integrate your treatment into your daily routine even if it means } \\
\text { taking medication or doing other things in front of people who don't } \\
\text { know you are HIV-infected. }\end{array}$ & $\begin{array}{l}7.19 \\
(2.81)\end{array}$ & $\begin{array}{l}7.56 \\
(2.55)\end{array}$ & $\begin{array}{l}6.84 \\
(3.03)\end{array}$ & 0.187 \\
\hline $\begin{array}{l}\text { 4. Stick to your treatment schedule even when your daily routine is } \\
\text { disrupted. }\end{array}$ & $\begin{array}{l}7.89 \\
(2.57)\end{array}$ & $\begin{array}{l}8.21 \\
(2.40)\end{array}$ & $\begin{array}{l}7.60 \\
(2.73)\end{array}$ & 0.219 \\
\hline 5. Stick to your treatment schedule when you aren't feeling well. & $\begin{array}{l}7.84 \\
(2.51)\end{array}$ & $\begin{array}{l}8.27 \\
(2.06)\end{array}$ & $\begin{array}{l}7.45 \\
(2.84)\end{array}$ & 0.083 \\
\hline $\begin{array}{l}\text { 6. Stick to your treatment schedule when it means changing your } \\
\text { eating habits. }\end{array}$ & $\begin{array}{l}7.60 \\
(2.15)\end{array}$ & $\begin{array}{l}8.12 \\
(1.99)\end{array}$ & $\begin{array}{l}7.14 \\
(2.22)\end{array}$ & 0.017 \\
\hline $\begin{array}{l}\text { 7. Continue with your treatment even if doing so interferes with your } \\
\text { daily activities. }\end{array}$ & $\begin{array}{l}7.87 \\
(2.38)\end{array}$ & $\begin{array}{l}8.19 \\
(2.11)\end{array}$ & $\begin{array}{l}7.59 \\
(2.61)\end{array}$ & 0.186 \\
\hline $\begin{array}{l}\text { 8. Continue with the treatment plan your physician prescribed even if } \\
\text { your T-cells drop significantly in the next three months. }\end{array}$ & $\begin{array}{l}7.53 \\
(2.48)\end{array}$ & $\begin{array}{l}8.00 \\
(2.09)\end{array}$ & $\begin{array}{l}7.10 \\
(2.75)\end{array}$ & 0.055 \\
\hline $\begin{array}{l}\text { 9. Continue with your treatment even when you are feeling discouraged } \\
\text { about your health. }\end{array}$ & $\begin{array}{l}8.04 \\
(2.30)\end{array}$ & $\begin{array}{l}8.35 \\
(1.90)\end{array}$ & $\begin{array}{l}7.79 \\
(2.61)\end{array}$ & 0.203 \\
\hline $\begin{array}{l}\text { 10. Continue with your treatment even when getting to your clinic } \\
\text { appointments is a major hassle. }\end{array}$ & $\begin{array}{l}7.85 \\
(2.52)\end{array}$ & $\begin{array}{l}8.25 \\
(2.07)\end{array}$ & $\begin{array}{l}7.48 \\
(2.86)\end{array}$ & 0.107 \\
\hline $\begin{array}{l}\text { 11. Continue with your treatment even when people close to you tell } \\
\text { you that they don't think that it is doing any good. }\end{array}$ & $\begin{array}{l}8.21 \\
(2.36)\end{array}$ & $\begin{array}{l}8.67 \\
(1.70)\end{array}$ & $\begin{array}{l}7.79 \\
(2.80)\end{array}$ & 0.047 \\
\hline $\begin{array}{l}\text { 12. Get something positive out of your participation in treatment, even } \\
\text { if the medication you are taking does not improve your health. }\end{array}$ & $\begin{array}{l}7.77 \\
(2.61)\end{array}$ & $\begin{array}{l}8.25 \\
(2.12)\end{array}$ & $\begin{array}{l}7.74 \\
(2.36)\end{array}$ & 0.035 \\
\hline
\end{tabular}

Overall mean HIV-ASES score was $7.79 \pm 1.95$ (the maximum attainable score was 10). The items with reported lowest scores $(7.19 \pm 2.81)$ was "integrate treatment plan into the daily routine even if it means taking medication or doing other things in front of people who do not know you are HIV infected"; the mean score was lower in male $(6.84 \pm 3.03)$ than female $(7.56 \pm 2.55)$, but not reach statistically significant difference. Meanwhile, the item with highest score was "continue with your treatment even when people close to you tell you that they don't think that it is doing any good."

There was a trend towards higher HIV adherence self-efficacy in female when compared to male AYA-PHIV, but not statistically significant (the overall mean scores $8.16 \pm 1.67$ vs. $7.46 \pm 2.14$, respectively; $p=0.062$ ). There 
were 3 item scores which significantly higher in female when compared to male AYA. The first was "continue with your treatment even when people close to you tell you that they don't think that it is doing any good." (8.67 \pm 1.70 vs. $7.79 \pm 2.80$, respectively; $p=0.047$ ). The second was "get something positive out of your participation in treatment, even if the medication you are taking does not improve your health" ( $8.25 \pm 2.12$ vs. $7.74 \pm 2.36$, respectively; $p=0.035)$. The third was "stick to your treatment schedule when it means changing your eating habits" ( $8.12 \pm 1.99$ vs. $7.14 \pm 2.22$, respectively; $p=0.017)$. Correlation between HIV adherence self-efficacy and overall QOL was observed $(r=0.268, p=0.005)$.

\section{Discussion}

With effective ART, today there are increasing number of AYA-PHIV in communities. QOL has become another outcome of interest, both in studies of HIV/AIDS treatment outcomes and in clinical practice. To healthcare providers, the desire health outcome was not to have them grow physically, but also to let them depart and enter adult life healthily in all aspects. Nearly $60 \%$ of AYA-PHIV on ART who participated in this study rated their QOL as favorable (good or very good). Higher scores were rated in the social relationship and environment health domains than in the physical health and psychological health domains. Their overall HIV-ASES was optimal and positively correlated with QOL.

The previous study evaluated the QOL of younger Thai and Cambodian children (mean age 6.3 years) with PHIV using parental proxy report (7). They documented lower QOL among children living with HIV when compared to healthy control without HIV. In our study most of AYA-PHIV perceived their QOL as favorable, while we did not have comparison group. We presumed that when study participants completed the questionnaire by themselves, satisfaction is a feeling in relative to their expectation on each item, which was inadvertently being compared to their peers or siblings.

The Spanish study in youth with PHIV at the median age of 23.36 years reported lower scores in physical health subscale when compared to HIV negative. The mental health subscale score was also lower than the references values for general youths in their country (11). Similarly, we found low mean scores in physical and psychological health domains. Nevertheless, they mentioned better scores observed in participants who were in school obtained than those who were working, which was in contrast with our findings. Thai AYA who were studying had lower overall QOL scores when compared to those who worked. This might be explained by financial constraint, academic-related stress as a result of neurocognitive impairment, peer pressure, or anticipated HIV-related stigma. The actual associated factors are needed to be further explored using different approaches i.e. semi-structural or in-depth interview technics.

Resilience might have a role in maintain favorable QOL among AYA with PHIV. Fortunately, the previous study in Thai and Cambodian children living with HIV revealed similar rates of resilience among children with PHIV when compared to peers without HIV (21). The French study in adolescents with PHIV at the median age of 16 years reported that majority of them had medium to high level of life satisfaction, HIV had only minor impact on their daily life and they had positive expectation towards adulthood (22). Similarly, majority of Thai AYA in this study were found to have good self-esteem and positive feeling on themselves. Although negative feelings were not uncommon; it was known that depression is among mental health challenges in AYA-PHIV (23).

The social relationship domain scores were summarized of responses from questions about personnel relationship, social support, and sexual relationship. Social support, defined as an availability of people who let 
an individual know that they care about, value, and love them, has reported to have a positive effect on the QOL of people living with HIV/AIDS. Perceived social support mediated hope and overall satisfaction which were significant for people living with HIV/AIDS and their families to keep a positive attitude $(24,25)$. The US study observed significantly lower levels of depression and fewer conduct problems in adolescents whose parents were infected with HIV revealed that with more social support (26). The Chinese study revealed a better QOL among young men who have sex with men living with HIV who had greater social support (27). This domain is believed to be an important component which affected overall QOL.

The multi-regional study included western countries, Namibia and China documented effect of healthcare provider engagement on self-efficacy, self-esteem, medical adherence, and QOL of people living with HIV (28). In this study most participants have been under HIV care since childhood, and continuing followed up to present. Some participants have never seen by our team before, but they were familiar with health care staff and hospital system. The long standing provider-client relationship might explain their positive feeling revealed in the study results. Nevertheless, the relationship could not last longer beyond early adulthood, as there was a need for transition of care, either to adult clinic or other hospitals per their health care coverage programs. Apart from engaging them to various types of social network outside health care setting, it was important that we strengthen to maximize their self-esteem and self-efficacy so that they could left with confidence and trust.

The environmental domain score was the highest among four domain scores rated by AYA-PHIV in this study. However, the dissatisfaction in physical environment as rated by $30.6 \%$ of study participants could be explained by the seasonal air pollution. The data collection was performed at the end of winter to early summer when many provinces in northern Thailand including Chiang Mai were covered with smog. The opportunity to acquire information were not problematic to AYA in this era with internet and many information technologies. Most satisfied with their home environment, freedom, as well as safety and security. Transportation was rated as dissatisfied by $10.8 \%$ of study participants. It was most likely due to the limitation of infrastructure, unavailability of public transport services in the study location. We perceived that many factors in this domain was not HIVrelated variables. The environment might not be perfect, but the fact that AYA-PHIV could enjoy them in the same way as everyone in their residential area make the high rated scores.

In this study we did not find any predictor of QOL in AYA-PHIV. It was possible that many unidentified confounders exist in their transitional period of life that have influence on their QOL, not the common variables we focused on. However, a factor with a trend to affect QOL, although did not reach statistical significant level was ART regimen. Efavirenz-based ART regimen was a once daily dosing medication with low pill burden ( $\leq 3$, often single pill) that was more convenience to take when compared to the twice daily nevirapine, or protease-based regimen which might be once daily but usually composed of many pills.

Having biological parents as a primary caregiver during childhood was found to associate with unfavorable QOL. There was a possibility that many AYA-PHIV who have risen up under care of their biological parents might have faced loss and grief when their parents died. Other issues might be socio-economic problem related to parental HIV infection i.e. limited working ability, experienced stigma and discrimination, or family member with illnesses, all could affect overall QOL of AYA-PHIV.

Perceived self-efficacy is an important determinant of disease management. For individuals living with HIV, it included several abilities to manage schedules, situations, stress, and utilization of resources in order to accomplish medication adherence. Meanwhile, both self-efficacy and adherence were significant predictors of 
QOL according to the Chinese study (17). In our study, a trend towards higher self-efficacy was seen in female over male AYA-PHIV. The items with reported lowest scores was the one related to social stigma ("integrate treatment plan into the daily routine even if it means taking medication or doing other things in front of people who do not know you are HIV infected"). This item indicated the outstanding role of HIV-related stigma as a barrier against adhering to treatment plan. It was in line with the US study among caregivers who looking after children with PHIV (14). Those caregivers who did well in HIV knowledge assessment and also rated themselves as having high adherence self-efficacy had less confident in ability to adhere to ART if it might result in social disclosure. This issue is noteworthy as it could underlie suboptimal HIV treatment adherence, and wide range of interventions aims at community level is required to reduce HIV-related stigma. In our findings, female was found to have more self-confident, stronger belief in ART, and more flexible in daily routine when came to the need to adhere with medication schedule when compared to male AYA. In designing intervention, as well as daily counselling, we might have to pay more attention on male and find the best approach to improve their HIV adherence self-efficacy.

The study had several limitations. First, it was a single site study, our study participants were quite homogenous and had similar demographic characteristics. Second was the issue of sampling bias, as we enrolled AYA who came to HIV clinic and willing to join the study, their QOL were supposed to be better those who LTFU from the cascade, too sick to be independent, did not come to the hospital, or did not want to participate on researches. Third, we did not assess HIV knowledge or VL outcome to see whether they associated with HIV adherence selfefficacy or not. Lastly, assessment of QOL using self-administer questionnaire has a limitation itself. We did not know what they thought, or the reason behind each answer which might be more complicate than we could imagine of. Further study using focus group discussion, in-depth interview, or mix-methods study design might allow us to explore, probe, and learn more about the well-being of AYA-PHIV.

In conclusion, the study results revealed that most of AYA-PHIV in Thailand had a favorable QOL and optimal HIVadherence self-efficacy. Future attention should be paid on strengthen their physical and psychological health, with continuous social support. Intervention to boost their HIV-adherence self-efficacy when entering adult life is warranted.

\section{Declarations}

\section{- Ethical approval and consent to participate}

The study was approved by the institutional review boards at the Research Institute for Health Sciences, Chiang Mai University (Certificate approval number 48/2017), and the Chiang Mai University Faculty of Medicine. Written informed consent was obtained from each participant prior to enrollment. Parental consent and assent were obtained for those under 18 years of age.

- Consent for publication

Not applicable

- Availability of data and materials

The datasets used and/or analysed during the current study are available from the corresponding author on reasonable request.

Page 12/15 
- Competing of interest

The authors declare that they have no completing interests.

- Funding

The study was funded by Chiang Mai University, Chiang Mai, Thailand

- Authors' contributions

LA, NW, and TAS designed and prepared the study; LA, CP, NW, TAC conducted the study; KMS and TACcompiled, cleaned, and computed the data, which were analysedand interpreted by LA; LA, CP, and KMS wrote the manuscript, which was critically revised by NW, TAC, and TAS; all authors have approved this version of the manuscript and agree with the submission. LA is the guarantor.

- Acknowledgements

We thank all adolescents and young adults, and their caregivers for their devoted time joining in this study. We would like to also thank the study staff who conducted data collection, and HIV clinic staff who helped in coordinating study activities and routine services.

\section{References}

1. UNAIDS. Global HIV \& AIDS statistics - 2019 fact sheet2019 24 Mar 2020. Available from: https://www.unaids.org/en/resources/fact-sheet.

2. Mellins CA, Malee KM. Understanding the mental health of youth living with perinatal HIV infection: lessons learned and current challenges. J Int AIDS Soc. 2013;16:18593.

3. Sohn AH, Chokephaibulkit K, Lumbiganon P, Hansudewechakul R, Gani YM, Van Nguyen L, et al. Peritransition Outcomes of Southeast Asian Adolescents and Young Adults With HIV Transferring From Pediatric to Adult Care. J Adolesc Health. 2020;66(1):92-9.

4. The World Health Organization Quality of Life Assessment (WHOQOL): development and general psychometric properties. Soc Sci Med. 1998;46(12):1569-85.

5. Webster P. UNAIDS survey aligns with so-called fourth 90 for HIV/AIDS. Lancet. 2019;393(10187):2188.

6. Malee KM, Tassiopoulos K, Huo Y, Siberry G, Williams PL, Hazra R, et al. Mental health functioning among children and adolescents with perinatal HIV infection and perinatal HIV exposure. AIDS Care. 2011;23(12):1533-44.

7. Bunupuradah T, Kosalaraksa P, Vibol U, Hansudewechakul R, Sophonphan J, Kanjanavanit S, et al. Impact of antiretroviral therapy on quality of life in HIV-infected Southeast Asian children in the PREDICT study. AIDS Patient Care STDS. 2013;27(11):596-603.

8. Aurpibul L OP, Choeyprasert W, Louthrenoo O. Health-related quality of life of perinatally HIV-infected adolescents. Curr Pediatr Res. 2016;20(1\&2):231-7.

9. Nkwata AK, Zalwango SK, Kizza FN, Sekandi JN, Mutanga J, Zhang M, et al. Quality of life among perinatally HIV-affected and HIV-unaffected school-aged and adolescent Ugandan children: a multi-dimensional assessment of wellbeing in the post-HAART era. Qual Life Res. 2017;26(9):2397-408. 
10. Cohen S, ter Stege JA, Weijsenfeld AM, van der Plas A, Kuijpers TW, Reiss P, et al. Health-related quality of life in perinatally HIV-infected children in the Netherlands. AIDS Care. 2015;27(10):1279-88.

11. Cuellar-Flores I, Sainz T, Velo C, Gonzalez-Tome MI, Garcia-Navarro C, Fernandez-Mcphee C, et al. Impact of HIV on the health-related quality of life in youth with perinatally acquired HIV. World J Pediatr. 2019;15(5):492-8.

12. Nachega JB, Hislop M, Dowdy DW, Chaisson RE, Regensberg L, Maartens G. Adherence to nonnucleoside reverse transcriptase inhibitor-based HIV therapy and virologic outcomes. Ann Intern Med. 2007;146(8):56473.

13. Kim SH, Gerver SM, Fidler S, Ward H. Adherence to antiretroviral therapy in adolescents living with HIV: systematic review and meta-analysis. AIDS. 2014;28(13):1945-56.

14. Nicholson O, Mellins C, Dolezal C, Brackis-Cott E, Abrams EJ. HIV treatment-related knowledge and selfefficacy among caregivers of HIV-infected children. Patient Educ Couns. 2006;61(3):405-10.

15. Bandura A. Human agency in social cognitive theory. Am Psychol. 1989;44(9):1175-84.

16. Peters M, Potter CM, Kelly L, Fitzpatrick R. Self-efficacy and health-related quality of life: a cross-sectional study of primary care patients with multi-morbidity. Health Qual Life Outcomes. 2019;17(1):37.

17. Huang L, Li L, Zhang Y, Li H, Li X, Wang H. Self-efficacy, medication adherence, and quality of life among people living with HIV in Hunan Province of China: a questionnaire survey. J Assoc Nurses AIDS Care. 2013;24(2):145-53.

18. WHOQOL-BREF: Introduction, Administration, Scoring and Generic Version of the Assessment1996. Available from: https://www.who.int/substance_abuse/research_tools/en/thai_whoqol.pdf.

19. Sakthong P, Schommer JC, Gross CR, Sakulbumrungsil R, Prasithsirikul W. Psychometric properties of WHOQOL-BREF-THAI in patients with HIV/AIDS. J Med Assoc Thai. 2007;90(11):2449-60.

20. Johnson MO, Neilands TB, Dilworth SE, Morin SF, Remien RH, Chesney MA. The role of self-efficacy in HIV treatment adherence: validation of the HIV Treatment Adherence Self-Efficacy Scale (HIV-ASES). J Behav Med. 2007;30(5):359-70.

21. Malee KM, Kerr S, Paul R, Puthanakit T, Thongpibul K, Kosalaraksa P, et al. Emotional and behavioral resilience among children with perinatally acquired HIV in Thailand and Cambodia. AIDS. 2019;33 Suppl 1:S17-S27.

22. Funck-Brentano I, Assoumou L, Veber F, Moshous D, Frange P, Blanche S. Resilience and Life Expectations of Perinatally HIV-1 Infected Adolescents in France. Open AIDS J. 2016;10:209-24.

23. Vreeman RC, McCoy BM, Lee S. Mental health challenges among adolescents living with HIV. J Int AIDS Soc. 2017;20(Suppl 3):21497.

24. Yadav S. Perceived social support, hope, and quality of life of persons living with HIV/AIDS: a case study from Nepal. Qual Life Res. 2010;19(2):157-66.

25. Li XM, Yuan XQ, Wang JJ, Zhang WY, Zhou Y, Liu GN. Evaluation of impact of social support and care on HIV-positive and AIDS individuals' quality of life: a nonrandomised community trial. J Clin Nurs. 2017;26(34):369-78.

26. Lee SJ, Detels R, Rotheram-Borus MJ, Duan N. The effect of social support on mental and behavioral outcomes among adolescents with parents with HIV/AIDS. Am J Public Health. 2007;97(10):1820-6. 
27. Jiang T, Zhou X, Wang H, Luo M, Pan X, Ma Q, et al. Psychosocial Factors Associated with Quality of Life in Young Men Who Have Sex with Men Living with HIV/AIDS in Zhejiang, China. Int J Environ Res Public Health. 2019;16(15).

28. Chen WT, Wantland D, Reid P, Corless IB, Eller LS, lipinge S, et al. Engagement with Health Care Providers Affects Self-Efficacy, Self-Esteem, Medication Adherence and Quality of Life in People Living with HIV. J AIDS Clin Res. 2013;4(11):256. 